\title{
Investigation on the effect of blending ratio and airflow rate on syngas profile produced from co-gasification of blended feedstock
}

\author{
Muddasser Inayat ${ }^{1, *}$, Shaharin Anwar Sulaiman ${ }^{1}$, and Jundika Candra Kurnia ${ }^{1}$ \\ ${ }^{1}$ Department of Mechanical Engineering, Universiti Teknologi PETRONAS, 32610 Bandar Seri \\ Iskandar, Perak Darul Ridzuan, Malaysia
}

\begin{abstract}
Shortages of feedstock supply due to seasonal availability, high transportation costs, and lack of biomass market are creating serious problems in continues operation of bioenergy industry. Aiming at this problem, utilization of blended feedstock is proposed. In this work blends of two different biomasses (wood and coconut shells) were co-gasified using externally heated downdraft gasifier. The effects of varying biomass blending ratio and airflow rate on gaseous components of syngas and its heating value were investigated. The results obtained from the experiments revealed that W20:CS80 blend yielded higher values for $\mathrm{H}_{2}(20 \mathrm{Vol} . \%)$ and $\mathrm{HHV}\left(18 \mathrm{MJ} / \mathrm{Nm}^{3}\right)$ as compared to the other blends. The higher airflow rate has a negative effect on syngas profile and heating value. The $\mathrm{CO}$ and $\mathrm{CH}_{4}$ were observed higher at the start of the process, however, $\mathrm{CO}$ was observed decreasing afterward, and the $\mathrm{CH}_{4}$ dropped to $5.0 \mathrm{Vol} . \%$. The maximum $\mathrm{H}_{2}$ and $\mathrm{CH}_{4}$ were obtained at 2.5 LPM airflow rate. The process was noticed more stable at low air flow rates. The HHV was observed higher at the start of process at low airflow rate. It is concluded that low airflow rate and a higher ratio of coconut shells can improve the syngas quality during cogasification.
\end{abstract}

\section{Introduction}

Malaysia is a tropical country blessed with plenty of biomasses by the nature especially forestry and palm oil industry. The biomasses from these sources could be potential feedstock for bioenergy industry via gasification [1]. It is projected that exploitation of forestry wastes and agricultural wastes will contribute significantly as the substitution of fossil fuel in the future [1]. Malaysian woodland and timber processing factories generate a huge amount of wood residue. These timber factories and woodland are considered as one of the major unexploited biomass sources in Malaysia. Malaysia has five wood mills, which are using the wood residue as fuel and each wood mill has potential to generate $900 \mathrm{~kW}$ to $10 \mathrm{MW}$ of energy. In 2010, 12 million $\mathrm{m}^{3}$ of timber logs were produced from the Malaysian forest area [2]. The wood waste generated during the logging operation was 5.1 million $\mathrm{m}^{3}$ in form of stumps, branches, bark, tops, broken logs, defective logs and injured standing trees. All these wastes are equal to $43 \%$ of total volume of the trees [3]. Beside this, coconut is also potentially available in Malaysia as a source of edible oil and coconut milk, and it is one of the main ingredient of most Malaysian foods. Coconut shells are the by-product of coconut milk processing industries, which can be utilized as potential feedstock for bioenergy [2].

Dependency on only a single biomass feedstock could be problematic for continuous gasification operation. It was reported that gasification of biomass often experienced the problems of unsteady supply of feedstock throughout the year due to various reasons such as; seasonal harvesting, high transportation cost, and climate change; for instance, flood, 
heavy rain and drought $[1,4]$. In addition, some biomass materials are available in small quantity and therefore, gasification process could not be sustained for longer periods. However, with co-gasification, the small amount of biomass could be meaningful as it can be mixed with other biomass materials to produce syngas for a prolonged period [5].

Although co-gasification of coal and biomass is extensively studied in the published literature. However, information about co-gasification is very rare [6, 7]. Therefore, residual of lignocellulosic biomasses such as wood and coconut shells are considered as a potential source of energy via co-gasification. The biomass feedstock mixtures have a strong influence on the resulting syngas composition [4]. In this study, co-gasification of wood and coconut shells was carried out using an externally heated downdraft gasifier. The effects of varying blending ratios and airflow rate on the gas profile of syngas components and its heating value were investigated.

\section{Materials and methodPreparation and characterization of feedstock}

Blends of wood and coconut shells (W/CS) at various ratios were used as feedstock for this study. The wood was collected from the landscape area of Universiti Teknologi PETRONAS Malaysia and coconut shells were collected from the local market at Batu Gajah, Perak, Malaysia. A lab-scale granulator machine was used for size reduction of feedstock in the range of $3-5 \mathrm{~mm}$ [8]. Characterization of wood and coconut shells includes ultimate analysis, proximate analysis, and heating value. The ultimate analysis was carried out as per ASTM D3176-09 in elementar vario MICRO CHNS analyzer. Proximate analysis was carried out on LABsys Evo TGA analyzer as per ASTM E1755-01. The moisture content feedstock was determined as per ASTM E871-82. According to ASTM D4809-00 standard procedure higher heating value of the feedstock was determined [9]. Characterization results are presented in Table 1.

Table 1. Characterization Results of Wood and Coconut Shells

\begin{tabular}{|c|c|c|c|c|c|c|c|c|c|c|c|c|}
\hline \multirow{2}{*}{ Feedstock } & \multicolumn{4}{|c|}{ Ultimate Analysis (\%) } & \multirow{2}{*}{ H/C } & \multirow{2}{*}{ O/C } & \multicolumn{3}{|c|}{ Proximate Analysis (\%) } & \multirow{2}{*}{ HHV(MJ/kg) } \\
\cline { 2 - 8 } & $\mathbf{C}$ & $\mathbf{H}$ & $\mathbf{N}$ & $\mathbf{S}$ & $\mathbf{O} *$ & & & MC & VM & FC* & Ash & \\
\hline Wood & 43.54 & 3.59 & 0.31 & 0.08 & 51.70 & 0.99 & 0.89 & 4.25 & 88.58 & 6.02 & 1.16 & 17.53 \\
\hline $\begin{array}{c}\text { Coconut } \\
\text { Shells }\end{array}$ & 46.93 & 3.96 & 1.33 & 0.25 & 48.21 & 1.01 & 0.77 & 2.29 & 82.09 & 14.79 & 0.83 & 19.43 \\
\hline
\end{tabular}

*On difference basis

\subsection{Experimental setup and experiment design}

The experiments were conducted using a batch type externally heated downdraft gasifier. The detail of experimental setup is presented in Fig. 1. Gasifier consisted of a cylindrical body surrounded by the ceramic electric furnace. The desired temperature of gasifier was controlled by a temperature microcontroller. A controlled and measured quantity of air was supplied. The airflow rate was regulated and measured by using a rotameter. The output syngas was channelled through a rubber tube which was passed through a pair of the filter. The filters trapped excess tar and moisture of syngas. A filtered syngas was pumped into the online gas analyzer to analyze its composition. A flare point was introduced between filter and gas pumping point to act as a buffer. Furthermore, flammability of the syngas was checked at flare point. Experiments were conducted for two varying parameters which were biomass blending ratio and airflow rate. The blends of W20:CS80, W50:CS50, and W80:CS20 were used and airflow rate was ranged from $2.0 \mathrm{~L} / \mathrm{min}$ to $4.0 \mathrm{~L} / \mathrm{min}$. All experiments were carried out at an optimum temperature of $800^{\circ} \mathrm{C}$. The details of experimental plan are presented in Table 2. 
Table 2. Experimental Conditions for Co-gasification of Wood/Coconut Shells

\begin{tabular}{|c|c|c|c|}
\hline Experiment & Temperature $\left({ }^{\circ} \mathbf{C}\right)$ & Airflow Rate (L/min) & Blending Ratio \\
\hline 1 & 800 & 3.0 & W20:CS80 \\
\hline 2 & 800 & 3.0 & W50:CS50 \\
\hline 3 & 800 & 3.0 & W80:CS20 \\
\hline 4 & 800 & 2.0 & W20:CS80 \\
\hline 5 & 800 & 2.5 & W20:CS80 \\
\hline 6 & 800 & 3.5 & W20:CS80 \\
\hline 7 & 800 & 4.0 & W20:CS80 \\
\hline
\end{tabular}

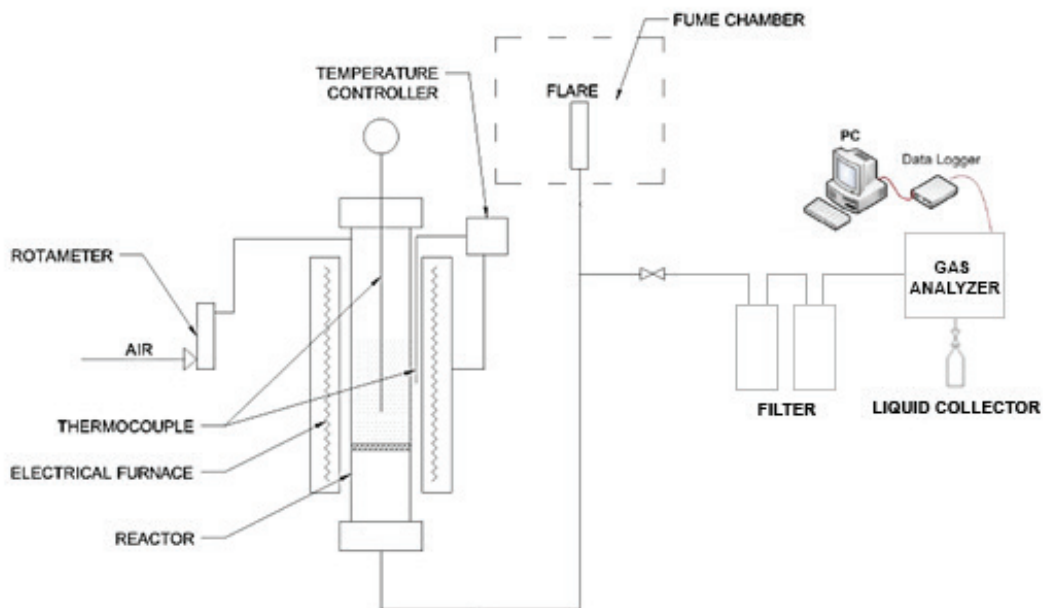

Fig. 1. Schematic diagram of experimental setup

\subsection{Experimental procedure}

The residual of ash and char of the previous experiments in gasifier was cleaned before to start the experiment. The gas piping was checked properly to ensure that there was no blockage in it. The gasifier temperature was set and monitored by the temperature microcontroller. The electric ceramic furnace was switched on 30 minutes before to start the experiment. As the desired temperature was obtained a pre-measured quantity of blended feedstock of W/CS was fed from the top of the gasifier. A control and measured air was supplied to the gasifier as gasification medium. The gas analyzer was connected to the computer via its interface Ethernet. A continues syngas was pumped to analyzer through diaphragm pump. The online analyzer software was used to record the syngas composition with an interval of 1 second. The syngas sampled was analyzed until all the feedstock was consumed. The interface of the gas analyzer was stopped and data was saved in a computer. The air supply was stopped and electric ceramic furnace was switched off so that gasifier was allowed to cool down. The residual of co-gasification such as ash and char from the gasifier was collected and was measured for further calculations.

The quality of syngas can be determined by the gas composition and its heating value. The heating value of a syngas is defined as the quantity of heat being released from combustion of a unit volume of syngas under the normal conditions. Higher heating value (HHV) also known as gross calorific value is the total energy released from syngas and can be determined by Eq. (1) $[4,6]$.

$\mathrm{HHV}_{\text {Syngas }}=12.63 \times X_{\text {co }}+12.74 \times X_{\mathrm{H}_{2}}+39.82 \times X_{\mathrm{CH}_{4}}$ 
where $\mathrm{HHV}$ of $\mathrm{CO}, \mathrm{H}_{2}$, and $\mathrm{CH}_{4}$ are $12.63 \mathrm{MJ} / \mathrm{Nm}^{3}, 12.74 \mathrm{MJ} / \mathrm{Nm}^{3}$, and $39.82 \mathrm{MJ} / \mathrm{Nm}^{3}$ respectively, and $\mathrm{X}_{\mathrm{CO}}, \mathrm{X}_{\mathrm{H} 2}$, and $\mathrm{X}_{\mathrm{CH} 4}$ represent the volumetric percentage of $\mathrm{CO}, \mathrm{H}_{2}$ and $\mathrm{CH}_{4}$ in dry syngas respectively [10].

\section{Results and discussion}

\subsection{Effect of blending ratio on gas composition and syngas heating value}

Effects of biomass blending ratios on of gas profile of different syngas components and its higher heating value (HHV) are illustrated in Figure 2. Experiments were conducted using W20:CS80, W50:CS50, and W80:CS20 blends at 3.0 LPM airflow rate and $800^{\circ} \mathrm{C}$ temperature. At the start of the co-gasification process, the yields of $\mathrm{CO}$ and $\mathrm{CH}_{4}$ gases were high and concentration of $\mathrm{H}_{2}$ was low. The $\mathrm{CO}$ with $44 \mathrm{Vol} \%$ was quite higher among other gaseous components However, its production was continuously seen decreasing until 320 seconds of the process after that its get stable to the $10-15 \mathrm{Vol} . \%$. The $\mathrm{CH}_{4}$ was also higher in yield at the start of a process which was around $30 \mathrm{Vol} . \%$ but in a later stage, after 120 seconds it sharply decreased to reach to $5.0 \mathrm{Vol} \% \%$ and gets stable after 320 seconds. The $\mathrm{H}_{2}$ yield was around 10 Vol.\% for W50:CS50 and W80:CS20 blends after the 380 seconds of the process. The $\mathrm{H}_{2}$ starts decreasing after 520 seconds and it drop to $3.0 \mathrm{Vol}$. \%. The $\mathrm{H}_{2}$ yield from W20:CS80 was quite high as compared to the other blends it reached its maximum value $20 \mathrm{Vol} \%$ at 400 seconds of the process after that it starts decreasing. At 600 seconds and onward of the process, all blends the gas components were dropped below $3.0 \mathrm{Vol} \%$ for $\mathrm{H}_{2}$ and $\mathrm{CH}_{4}$ whereas $\mathrm{CO}$ was below $10 \mathrm{Vol} . \%$ in each experiment data was recorded for 1000 seconds. The decreased in gas composition after 600 seconds was subjected to consumption of feedstock during the process. Syngas HHV was calculated from the real time gas composition by Equation 1. HHV was high at the start of the process due to the higher values of $\mathrm{CO}$ and $\mathrm{CH}_{4}$. The maximum value achieved around $18 \mathrm{MJ} / \mathrm{Nm}^{3}$. The $\mathrm{HHV}$ started decreasing after 200 seconds of the process and until 600 seconds it dropped to $2.0 \mathrm{Vol} . \%$. Among the other blends W20:CS80 blend has higher HHV as it shown in the Figure 2d a less steep curve of HHV for W20:CS80 blend. Overall W20:CS80 blend was better in gas composition and HHV as compared to other blends. Therefore, the later experiments of airflow rate were carried out using W20:CS80 blend.
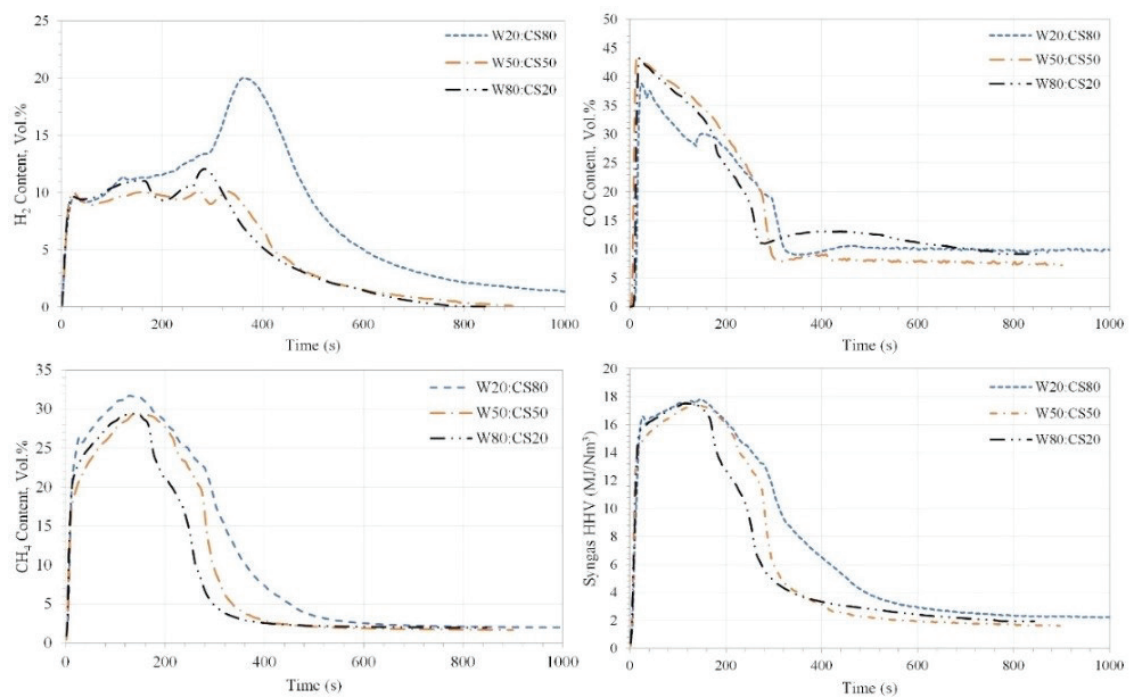

Fig. 2. Effect of biomass blending ratio on (a) $\mathrm{H}_{2}$, (b) $\mathrm{CO}$, (c) $\mathrm{CH}_{4}$, and (d) syngas higher heating value during the co-gasification of $\mathrm{W} / \mathrm{CS}$. 


\subsection{Effect of airflow rate on gas composition and syngas heating value}

The effect of airflow rate on the gas profile of different syngas components and syngas HHV is depicted in Figure 3. The blend of W20:CS80 was co-gasified at the $800^{\circ} \mathrm{C}$ temperature and airflow rate was varying from 2.0 to 4.0 LPM. The Figure 3 a presented the $\mathrm{H}_{2}$ profile at different airflow rate the $\mathrm{H}_{2}$ yield was increased from $20 \mathrm{Vol}$.\% to $30 \mathrm{Vol} . \%$ as the airflow rate decreased from 4.0 LPM to 2.0 LPM. Furthermore, the gas profile span also increased and shifted to the right side which shows that process was more stable at lower airflow rate range. The maximum $\mathrm{H}_{2}$ was obtained at 2.5 LPM close to pyrolysis conditions because of low air supply the reaction gets more time to complete the reaction through water-gas shift reaction $\left(\mathrm{CO}+\mathrm{H}_{2} \mathrm{O} \leftrightarrow \mathrm{CO}_{2}+\mathrm{H}_{2}\right.$ ) that is evidence of increasing $\mathrm{H}_{2}$ and decreasing $\mathrm{CO}$ at 400 seconds of the process in Figure $3 \mathrm{a}$ and $3 \mathrm{~b}$. All gas components start decreasing after the 400 seconds because the feedstock was near to consume. The $\mathrm{CH}_{4}$ was higher in yield at the start of the process (200 seconds) after that it starts decreasing. The highest $\mathrm{CH}_{4}$ content was obtained at low airflow rate. The Figure $3 \mathrm{~d}$ presented the HHV of syngas the HHV was also high at the start of the process due to higher production of all combustible gases at the start process. At low airflow rate range, the $\mathrm{HHV}$ was high due to the higher proportion of $\mathrm{H}_{2}$ content. The maximum HHV value was $18.40 \mathrm{MJ} / \mathrm{Nm}^{3}$ and it dropped to $3.0 \mathrm{MJ} / \mathrm{Nm}^{3}$ at the end of the process.
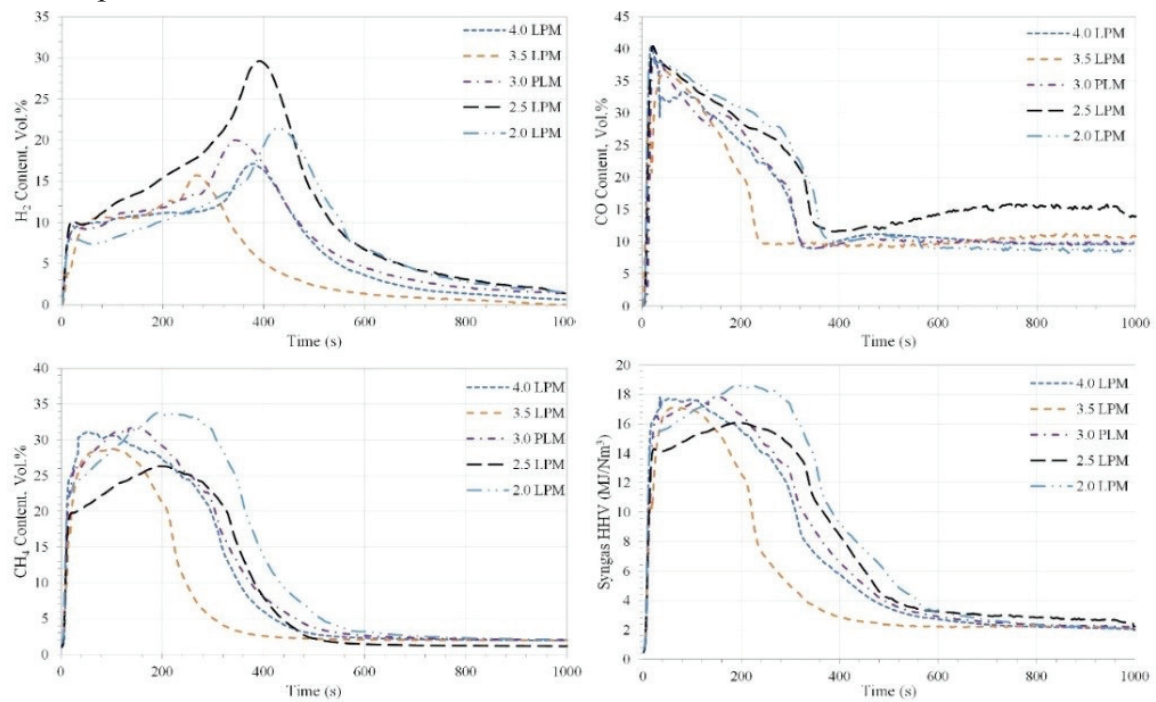

Fig. 3. Effect of airflow rate on (a) $\mathrm{H}_{2}$, (b) $\mathrm{CO}$, (c) $\mathrm{CH}_{4}$, and (d) syngas higher heating value during the co-gasification of W/CS.

\section{Conclusions}

In this paper, the co-gasification of wood and coconut shells blends was carried out using an externally heated gasifier. The effect of varying biomass blending ratios and airflow rate on the gas profile of syngas components and its HHV was investigated. The W20:CS80 blend is observed to have higher $\mathrm{H}_{2}$ as compared to other blends. The $\mathrm{H}_{2}$ yield has a negative correlation with airflow rate. A $50 \%$ increase in $\mathrm{H}_{2}$ yield was observed when the airflow rate decreased from 4.0 LPM to 2.0 LPM. The CO has a constant decreasing trend in biomass blending ratio and airflow rate. The $\mathrm{CH}_{4}$ yield increased at low airflow rate. The HHV was higher at the start of process and also at low airflow rate. It is concluded that low airflow rate and a higher proportion of coconut shells in blend can improve the syngas quality and process can be more stable with a lower airflow rate. 


\section{References}

1 M. Inayat, S. A. Sulaiman, A. Abd Jamil, F. M. Guangul, and S. M. Atnaw, "The study of temperature profile and syngas flare in co-gasification of biomass feedstock in throated downdraft gasifier," in ICGSCE 2014: Proceedings of the International Conference on Global Sustainability and Chemical Engineering, M. A. Hashim, Ed., ed Singapore: Springer Singapore, 2015, pp. 203-10.

2 S. M. Shafie, T. M. I. Mahlia, H. H. Masjuki, and A. Ahmad-Yazid, "A review on electricity generation based on biomass residue in Malaysia," Renewable and Sustainable Energy Reviews 2012;16(8): 5879-89

3 H. W. Kong, "Current status of biomass utilizations in Malaysia," Forest Research Institute Malaysia 2000.

4 S. A. Sulaiman, R. Roslan, M. Inayat, and M. Yasin Naz, "Effect of blending ratio and catalyst loading on co-gasification of wood chips and coconut waste," Journal of the Energy Institute

5 B. Buragohain, P. Mahanta, and V. Moholkar, S., "Investigations in gasification of biomass mixtures using thermodynamic equilibrium and semi-equilibrium models," International Journal of Energy and Environment 2011;2(3): 551-78

6 M. Inayat, S. A. Sulaiman, A. Kumar, and F. M. Guangul, "Effect of fuel particle size and blending ratio on syngas production and performance of co-gasification," Journal of Mechanical Engineering and Sciences 2016;10(2): 2187-99

7 S. A. Sulaiman, M. Inayat, H. Basri, F. M. Guangul, and S. M. Atnaw, "Effect of blending ratio on temperature profile and syngas composition of woody biomass co-gasification," Journal of Mechanical Engineering and Sciences 2016;10(2): 2176-86

8 M. N. Z. Moni, S. A. Sulaiman, Y. S. Raja, K. Karunamurthy, M. Inayat, and M. A. BouRabee, "Investigation of the relationship between moisture content and density of selected Malaysian biomass " Journal of Mechanical Engineering and Sciences 2016;10(2): 211125

9 S. A. Sulaiman, H. S. Bamufleh, S. N. A. Tamili, M. Inayat, and M. Yasin Naz, "Characterization of date palm fronds as a fuel for energy production," Bulletin of the Chemical Society of Ethiopia 2016;30(3): 465-72

10 P. Basu, Biomass gasification and pyrolysis: practical design and theory: Academic press, 2010. 